\title{
Effects of Erosion from Mounds of Different Termite Genera on Distinct Functional Grassland Types in an African Savannah
}

\author{
Cleo M. Gosling, ${ }^{1,4 *}$ Joris P. G. M. Cromsigt, ${ }^{2}$ Nokukhanya Mpanza, ${ }^{3}$ \\ and Han Olff ${ }^{1}$
}

\begin{abstract}
${ }^{1}$ Community and Conservation Ecology Group, Centre for Ecological and Evolutionary Studies, University of Groningen, PO Box 11103, 9700 CC Groningen, The Netherlands; ${ }^{2}$ Centre for Ecological and Evolutionary Synthesis, Department of Biology, University of Oslo, PO Box 1066, Blindern 0316, Oslo, Norway; ${ }^{3}$ Scientific Services, Kruger National Park, South African National Parks, Skukuza 1350, South Africa; ${ }^{4}$ Leopard Ecology and Conservation, Private Bag BR 7, Gaborone, Botswana
\end{abstract}

\begin{abstract}
A key aspect of savannah vegetation heterogeneity is mosaics formed by two functional grassland types, bunch grasslands, and grazing lawns. We investigated the role of termites, important ecosystem engineers, in creating high-nutrient patches in the form of grazing lawns. Some of the ways termites can contribute to grazing lawn development is through erosion of soil from aboveground mounds to the surrounding soil surface. This may alter the nutrient status of the surrounding soils. We hypothesize that the importance of this erosion varies with termite genera, depending on feeding strategy and mound type. To test this, we simulated erosion by applying mound soil from three termite genera (Macrotermes, Odontotermes, and Trinervitermes) in both a field experiment and a greenhouse experiment. In the greenhouse experiment, we found soils with the highest macro nutrient levels
\end{abstract}

(formed by Trinervitermes) promoted the quality and biomass of both a lawn (Digitaria longiflora) and a bunch (Sporobolus pyramidalis) grass species. In the field we found that soils with the highest micro nutrient levels (formed by Macrotermes) showed the largest increase in cover of grazing lawn species. By linking the different nutrient availability of the mounds to the development of different grassland states, we conclude that the presence of termite mounds influences grassland mosaics, but that the type of mound plays a crucial role in determining the nature of the effects.

Key words: bunch grass; ecosystem engineers; mound erosion; heterogeneity; Hluhluwe iMfolozi Park; lawn grass; savannah; termites; Macrotermitinae; Nasutitermitinae.
Received 5 March 2011; accepted 19 September 2011;

published online 2 November 2011

Author Contributions: Cleo M. Gosling performed the research, analyzed the data and wrote the paper. Joris P. G. M. Cromsigt conceived the design of the greenhouse experiment, helped with data analysis and writing of the paper. Nokukhanya Mpanza helped perform the research. Han Olff conceived the design of the field experiment and helped with data analysis.

*Corresponding author; e-mail: cleograf@gmail.com

\section{INTRODUCTION}

Identifying the underlying processes responsible for creating and maintaining spatial heterogeneity is a major theme in savannah ecology (Scholes and Walker 1993; Du Toit and others 2003; OwenSmith 2004; Sinclair and others 2008). A key aspect of the vegetation heterogeneity in many savannah 
grasslands are the mosaics formed by two functional grassland types, bunch grasslands and grazing lawns (Archibald 2008; Cromsigt and Olff 2008; Bonnet and others 2010). Grazing lawns consist of a community of short statured, stoloniferous, grazing tolerant grasses that are key resource areas for savannah herbivores (Grant and Scholes 2006; Verweij and others 2006; Stock and others 2009). There is considerable debate about the conditions that allow the establishment and maintenance of grazing lawns (Archibald 2008; Cromsigt and Olff 2008). However, there seems general consensus that two main conditions are important for the establishment of lawns; firstly, the tall grass layer has to be disturbed to remove competition for light by these tall grasses (Huisman and Olff 1998) and secondly, increased soil nutrient availability facilitates the spread of lawn grasses by allowing them to compensate losses and cover ground, faster than bunch grasses (Coughenour 1985; Scholes and Walker 1993; Young and others 1995; Cromsigt and Olff 2008). Termites are important ecosystem engineers (Jones and others 1997; Bignell 2000; Bignell and Eggleton 2000; Lavelle 2002; Lavelle and others 2006) that may provide both these conditions because they disturb the tall grass layer (Lee and Wood 1971; Pomeroy 1983; Spain and McIvor 1988; Lobry de Bruyn and Conacher 1990), and influence soil characteristics (Jouquet and others 2005a; Jouquet and others 2007). Therefore, they may be important in the establishment of grazing lawns.

It has been shown that termites affect soil conditions, including nutrient availability and texture (Eggleton and others 1996; Konate and others 1998; Jouquet and others 2004a; Jouquet and others 2005b), vegetation composition (Spain and McIvor 1988; Moe and others 2009; Fox-Dobbs and others 2010) and remove large quantities of primary production (Hopkins 1966; Wood and others 1978; Deshmukh 1989; Davies and others 2010). Another potentially important effect of termites is through the soil erosion from termite mounds which might contribute nutrient rich material to the surrounding soil (Coventry and others 1988; Holt and Coventry 1990). In African savannahs erosion from termite constructions is estimated to provide $10,000 \mathrm{~kg}$ of soil per hectare per year (Wood 1988). Given the ubiquitous and widespread distribution of termites throughout savannahs (Wood and others 1978; Ferrar 1982a; Uys 2002) and biomasses estimated to equal that of large herbivores (Ferrar 1982b; Deshmukh 1989; Moe and others 2009), this nutrient enrichment through mound erosion may contribute significantly to vegetation heterogeneity in savannahs (Smith and Yeaton 1998). However, empirical evidence for this is lacking.

When considering the impact of termite mound erosion, it is important to consider the diversity of termite genera present within this biome ( 54 genera recorded in Southern Africa, Uys 2002). Different taxa have a range of nesting, foraging and feeding habits and, hence, can differ markedly in the characteristics of their mound soils. Fungi harvesting termites, specifically the genus Macrotermes, have been most studied in savannahs (Darlington and Dransfield 1987; Dangerfield and others 1998; Jouquet and others 2004b; Moe and others 2009) with much less attention given to other genera. Also the majority of termite research has focused on studies of single species making comparisons of different species effects difficult (Sileshi and others 2010). In this study, we compared the effects of soil addition, from mound erosion, from mounds of three abundant termite genera (Macrotermes Holmgren 1909, Odontotermes Holmgren 1912 and Trinervitermes Holmgren 1912) (Figure 1). All three genera collect and feed on a variety of plant material, including large quantities of grass, and build their own unique, semi epigeal mounds (Uys 2002), and as a result locally disturb the tall grass layer. However, the method of feeding, mound size and function varies between them. Macrotermes build large robust mounds to create a micro-environment for symbiotic fungi (Noirot and Darlington 2000). Mounds are constructed from clay particles from deeper soil layers that increase the stability of the mound (Lobry de Bruyn and Conacher 1990; Holt and Lepage 2000; Jouquet and others 2004b) and are rich in minerals that are limited in surrounding savannah soils, such as $\mathrm{Ca}$ and Na (Lobry de Bruyn and Conacher 1990; Scholes and Walker 1993). Odontotermes also has symbiotic fungi but rarely builds mounds that extend far above the soil surface and are not characterized by increased clay content with the associated minerals. Finally, Trinervitermes mounds are smaller than the two previously described and are not used as a micro-environment for symbiotic fungi but to store gathered plant material. They are constructed from surface soil, mucus, and fecal matter (Uys 2002). This use of fecal material, rather than subsoil clay, and the concentration of harvested organic matter throughout the mound results in the enrichment of macronutrients $(\mathrm{N}, \mathrm{P})$ in these mound soils (Smith and Yeaton 1998; López-Hernández 2001; Ackerman and others 2007). We suggest that these different functions of the mounds result in different types of nutrient 

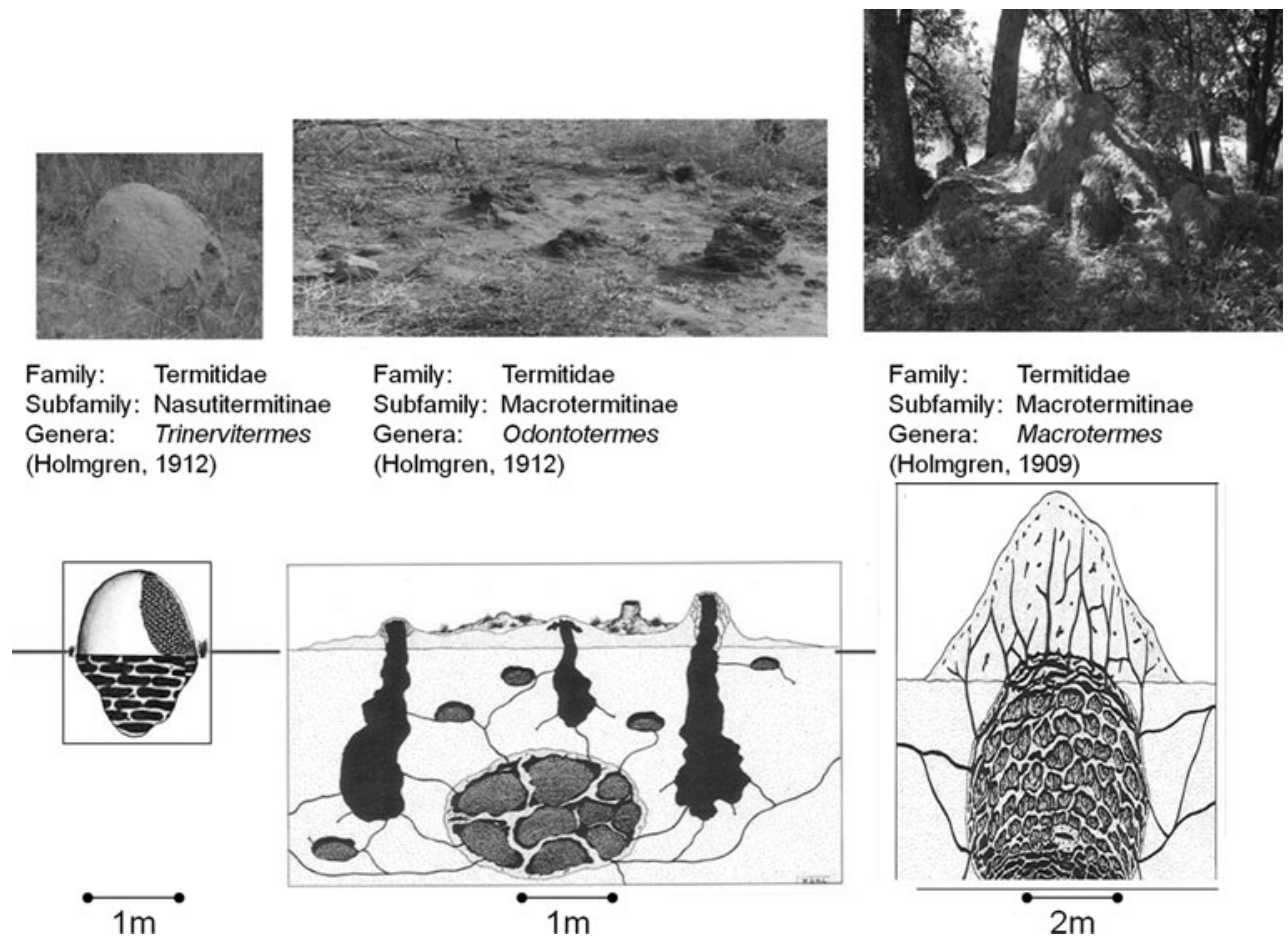

Figure 1. Pictures and schematic diagrams (taken from Uys 2002) with approximate scales, of the mounds built by the termite genera used in this study. Termites of all three genera feed on a variety of plant material, but all include grass in their diet. Mounds differ significantly between these genera. Trinervitermes use their mounds to store harvested grass material and as a result organic matter is found throughout their aboveground mounds. Aboveground parts of Odontotermes and Macrotermes mounds are primarily for climate control of the belowground fungal comb where the plant material is stored and, therefore, have little or no organic matter. Macrotermes mounds are large, aboveground structures that require high clay content for stability. This is mineral-rich soil that is transported by the termites from deeper soil layers. Odontotermes mounds are shallow humps with some chimney vents extending higher with less need for structural stability and therefore less clay, mineral rich, deep-soil than Macrotermes.

enrichment, which will play an important role in the effects of the mounds on the surrounding vegetation.

Having created the necessary disturbance to the tall grass layer by mound building and removing plant/grass material (Lee and Wood 1971; Pomeroy 1983; Spain and McIvor 1988; Lobry de Bruyn and Conacher 1990), we hypothesize that termite mound erosion might further contribute to savanna grassland heterogeneity and specifically to the development of grazing lawns. When mounds erode, they might increase the nutrient availability of the soil surface on, and surrounding, the mounds, which would further enhance colonization by lawn grasses (Cromsigt and Olff 2008). We suggest, however, that different termite genera, due to their different functional ecology, will differ in the effects of mound erosion on lawn development. Trinervitermes, due to the high organic content of their mounds, are likely to have a stronger effect than Macrotermes and Odontotermes.
To test this, we mimicked erosion from mounds of these three termite genera under field conditions. We cut the grass layer, to mimic termite disturbance, and spread mound soil across these cut grass patches, to mimic erosion effects. We then recorded changes in cover of lawn and bunch grass over the following 2-year period. We also conducted a greenhouse bio-assay where we tested the intrinsic effects of three different mound soils on grass performance, using a dominant lawn grass (Digitaria longiflora) and a dominant bunch grass (Sporobolus pyramidalis).

\section{MethodS}

\section{Study Site}

We conducted a field experiment in, and sampled soil and grasses from, Hluhluwe iMfolozi Park (HiP); a 90,000 ha protected area in KwaZulu-Natal South Africa (S $28^{\circ} 4^{\prime} 18.52^{\prime \prime}$, E $32^{\circ} 2^{\prime} 23.74^{\prime \prime}$ ). HiP occupies the foothills of the escarpment rising 
above the southeast African coastal plain, with altitudes ranging from 40 to $590 \mathrm{~m}$ above sea level. The average annual rainfall in HiP varies from 650 to $1000 \mathrm{~mm}$ and is strongly influenced by the altitudinal gradient running from the highest point in the northeast to the lowest in the southwest, respectively (Balfour and Howison 2001). The park is located within the southern Africa savannah biome with habitat ranging from open grasslands and thickets to closed Acacia and broad-leafed woodlands (Whateley and Porter 1983). There is a highly diverse assemblage of fauna and flora present (Brooks and others 1983). The park is characterized by strong small scale heterogeneity in grassland types. Grasslands dominated by tall bunch grass communities of S. pyramidalis, Eragrostis curvula, and Themeda triandra alternate with grasslands comprised of lawn grass communities of D. longiflora, Urochloa mosambicensis, Dactyloctenium australe, and Sporobolus nitens (Archibald and others 2005; Cromsigt and Olff 2006).

\section{Termites}

We focused on three termite genera; Macrotermes, Odontotermes, and Trinervitermes (Figure 1) which are common and widespread throughout the study site, with average densities of $1.25,0.37$, and 1.45 mounds per hectare, respectively (Table 1). Mound erosion is a significant factor with about $25 \%$ of all mounds showing damage to their structure (Table 1) and therefore likely to contribute significant amounts of eroded material to the surrounding area. Macrotermes and Odontotermes belong to the fungus growing subfamily Macrotermitinae. Both build large nest structures with semi-epigeal mounds and cultivate symbiotic fungi (Uys 2002). In this study, we used only soil from the aboveground, outer mound structure. Trinervitermes, belongs to the subfamily Nasutitermitinae which do not harvest fungi (Uys 2002). The mounds are smaller and more brittle than the Macrotermes and Odontotermes mounds. The termites are active and store food throughout the entire mound structure (personal observation) and therefore, despite best efforts, some plant material and termite carcasses were present in the treatment soil. Macrotermes natalensis and Trinervitermes trinervoides are known to be widespread throughout the region and are probably responsible for building the mounds used in this study. However, no Odontotermes has been identified to species level in the study area (Davies and Parr, personal communication).

\section{Greenhouse Experiment}

We performed a greenhouse bioassay experiment to study how the different mound soils affect growth rates, allocation patterns, and nutrient status of a typical lawn and bunch grass species in HiP. D. longiflora or False Couch Grass (here after referred to as lawn grass) is a palatable, stoloniferous grass species that forms extensive grazing lawns in HiP. S. pyramidalis or Catstail Dropseed (here after referred to as bunch grass) is a tough, poorly digestible species that forms erect tufts (Van Oudtshoorn 1992). We chose these two species because they are abundant representatives of lawn and bunch grasses in HiP, and dominated in the area surrounding our field experiment. Both were grown separately in the greenhouse, in pots with $500 \mathrm{~g}$ of one of the three termite genera mound soil

Table 1. Densities (Mounds/Hectares) of Macrotermes, Odontotermes, Trinervitermes Mounds in Hluhluwe iMfolozi Park

\footnotetext{
Live Macrotermes mounds with new material visible

Macrotermes mounds with no new material visible

Macrotermes mounds with slight damage

Macrotermes mounds with significant damage

Total Macrotermes mounds

Live Odontotermes mounds with new material visible

Odontotermes mounds with no new material visible

Odontotermes mounds with significant damage

Total Odontotermes mounds

Live Trinervitermes mounds with new material visible

Trinervitermes mounds with slight damage

Trinervitermes mounds with significant damage

Total Trinervitermes mounds

Total mounds
}

0.36
0.59
0.08
0.23
1.25
0.20
0.16
0.01
0.37
0.70
0.45
0.29
1.45
3.07

Densities were calculated by averaging counts of individual mounds made in 10,1 1 km blocks located throughout the park. 
or control soil (that is, 4 soil levels) for a period of 80 days. The soils were taken from 3 mounds of each genus within a $1 \mathrm{~km}^{2}$ block, from 10 blocks situated throughout HiP. The control soils were collected from surface, background soil, a minimum of $20 \mathrm{~m}$ from each mound. The three samples from each genus and each block were mixed to make a representative sample for each genus at each site. These samples from each block were kept separate and were treated as replicates. The pots were set out in a complete, randomized, block design and were moved regularly to account for potential variations in light and temperature in the greenhouse. In total, we had 10 blocks (replicates) of 8 pots representing all treatment combinations ( 4 soil levels and 2 grass species levels) resulting in 80 pots. Seedlings of Sporobolus were germinated from seeds collected in HiP and grown in growth chambers for 3-6 weeks before planting, ranging in longest leaf length from 60 to $107 \mathrm{~mm}$. Because the seedlings were small we planted two per pot. The Digitaria seeds did not germinate so live plants were collected from HIP, planted in potting soil and sand mix for 3 weeks after which small offshoots were harvested for use in the experiment. Because these were larger plants only one was used per pot. Because size of seedlings/offshoots differed significantly among individuals of the same species, we matched specimens of each species for size within each block (that is, the seedlings within a block were of similar size, but varied between blocks). The soil was kept at 20\% moisture (wet weight) by weighing and watering the pots twice weekly. No fertilizer was added throughout the experiment. Plant height, measured to the tip of the longest leaf, was recorded weekly to measure relative growth rate. After 80 days the plants were harvested by cutting each plant at soil level and splitting it into stems and leaf sections. Subsequently, the soil was carefully shaken and washed off the roots of each plant. All sections were dried at $70^{\circ} \mathrm{C}$ for $24 \mathrm{~h}$ before being weighed.

\section{Field Experiment}

In a field experiment, we studied how termitemodified soil affects the occurrence of lawn and bunch grasses under natural field conditions. The field experiment was located at 28.16826S, $31.96915 \mathrm{E}$, at an altitude of $210 \mathrm{~m}$, with annual rainfall of approximately $680 \mathrm{~mm}$ per annum. Treatment plots of $4 \times 4 \mathrm{~m}$ were set up with at least $4 \mathrm{~m}$ separating each plot. To avoid edge effects, all measurements were taken within a $4 \mathrm{~m}^{2}$ area at the center of the $4 \times 4 \mathrm{~m}$ plots. We used five treatments; Macrotermes mound soil, Odontotermes mound soil,
Trinervitermes mound soil, non-termite soil (taken from a pit at a depth of more than $20 \mathrm{~cm}$ ) and a control to which no soil was added. Each treatment was replicated five times using the Latin-square design where each row and column had one replicate of each treatment. Before adding soil to our treatment the grass was cut in all plots to a height of around $10 \mathrm{~cm}$ and the few woody species present were cut at soil level and all debris removed. Subsequently, on 29 October 2007 and 22 March 2008, we spread $20 \mathrm{l}$ of each soil type evenly over every appropriate plot, except the controls, and cut away any re-sprouted woody species. We collected the soil from several mounds of each genus from within a $1 \mathrm{~km}^{2}$ area of the experimental site and the nontermite soil from a pit dug within the same area. Each soil type was ground using a Culatti hammer mill to break up any lumps and well mixed before being spread. All soil samples were analyzed for various chemical and physical properties.

Prior to the clipping and application of the soil treatments, we recorded all plant species present and their ground coverage within the $4 \mathrm{~m}^{2}$ area per plot. Biomass was measured at five points within the same $4 \mathrm{~m}^{2}$ central area with a calibrated disc pasture meter (grass biomass in $\mathrm{g} / \mathrm{m}^{2}=12.6+26.1$ DPM (Waldram and others 2008)). After the treatment application, we recorded the percentage ground cover of four categories, allowing for a sum higher than $100 \%$ due to overlapping layers; \% bare soil, lawn grass, bunch grass, and forbs. All measurements were repeated monthly for a period of 16 months and once again 2 years after the start. Before the addition of treatment soil we sampled the dominant lawn (D. longiflora) and bunch (S. pyramidalis) grasses. Samples were taken from outside the central $4 \mathrm{~m}^{2}$ area of each plot. Multiple plants of each species were cut at ground level and subsequently sorted into live and dead, leaf and stem fractions, dried at $70^{\circ} \mathrm{C}$ for $24 \mathrm{~h}$ and each portion weighed separately. Digitaria was re-sampled once, 1 year after the start of the experiment. Sporobolus was not re-sampled as there was insufficient material present.

\section{Statistical Analysis}

The data from the greenhouse experiment were analyzed using a two-way analysis of variance (ANOVA), including plant species and soil treatment effects and their interaction, followed with Tukey's post hoc tests. During the field experiment, we repeatedly measured the same plots over time. To correct for any differences in starting conditions between the plots we used relative change, by 
subtracting the percentage values for each category at the start of the experiment from each subsequent month. To correct for temporal autocorrelation we used linear mixed-effect models, nesting our treatment within time (month). To correct for potential spatial autocorrelation, we also nested treatment within column which was possible due to our Latin-square design. We decided to nest within column as there was still a significant column effect despite the Latin-square design $\left(F_{4,276}=\right.$ 9.9318, $P<0.0001)$. We included column rather than row as the models were not significantly different but including column had a slightly lower AIC value $($ column $=2949$, row $=2952)$. In our final model, we specified soil treatment as a fixed effect and included one random effect where treatment was nested within column, within month. We used R, version 2.11.1, for all analysis.

\section{RESUlTS}

\section{Greenhouse Results}

In the greenhouse bioassay there were significant differences of total biomass with soil treatment $\left(F_{3,72}=27.79, P<0.001\right)$, between plant species $\left(F_{1,72}=4.60, P=0.04\right)$ (Figure 2$)$ and a significant interaction effect $\left(\mathrm{F}_{1,72}=3.96, P=0.01\right)$. Total

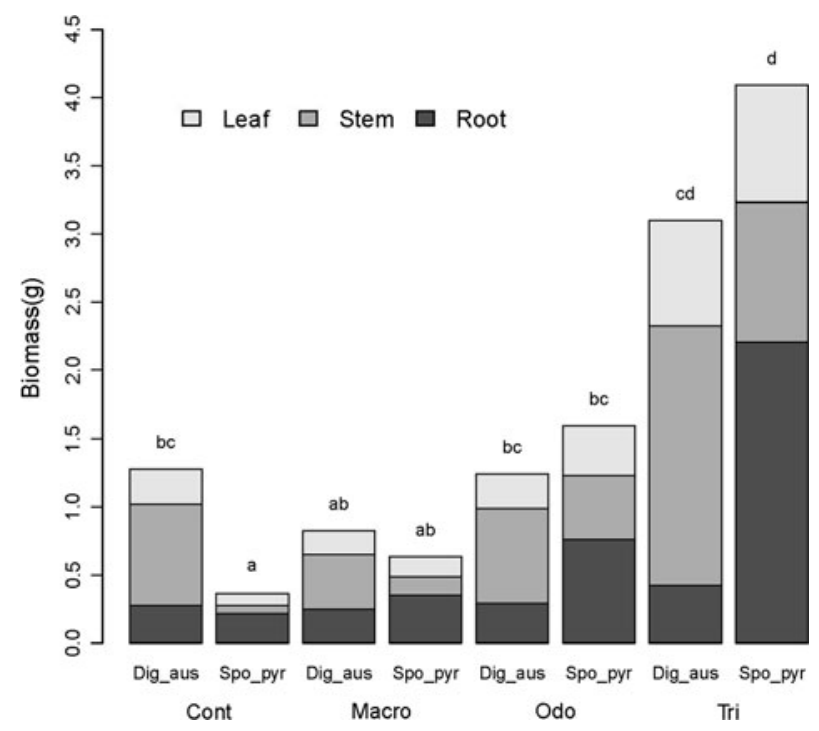

Figure 2. Greenhouse bioassay results; bar plot showing the differences in biomass ( $\mathrm{g}$ ) of the two grass species used, Dig_aus, Digitaria australe; Spo_pyr, Sporobolus pyramidalis in each soil treatment; Cont, Control soil; Macro, Macrotermes soil; Odo, Odontotermes soil; Tri, Trinervitermes soil. The data were log transformed for analysis; different letters denote significant differences $(P<0.05)$ in post-hoc Tukey's test. biomass was highest on Trinervitermes soils $\left(\mathrm{F}_{1,3}=32.9, P<0.001\right)$ but with no significant difference between plant species $\left(\mathrm{F}_{1,3}=0.30\right.$, $P=0.97)$ on this soil. The only significant difference between plants species was found on the control soil, where Sporobolus had significantly less biomass than Digitaria $\left(F_{1,3}=3.96, P=0.01\right)$.

There were significantly different allocation patterns between grass species (Figure 3). The lawn grass invested more in its stems than the bunch grass $\left(F_{1,72}=110.76, P<0.001\right)$ which was not affected by soil treatment $\left(F_{3,72}=2.14, P=0.10\right)$. The bunch grass generally had a larger root proportion than the lawn grass $\left(F_{1,72}=97.88\right.$, $P<0.001)$, and this was especially true on the Trinervitermes soil $\left(F_{3,72}=3.11, P=0.03\right)$. There was no difference in the leaf portion of the biomass between plants $\left(F_{1,72}=1.43, P=0.24\right)$ or treatments $\left(F_{3,72}=0.47, P=0.70\right)$.

Total nitrogen in the leaves was significantly different between soil treatments $\left(F_{3,72}=25.63\right.$, $P<0.001)$ with no difference between species $\left(F_{1,72}=1.13, P=0.34\right)$. The leaves contained twice as much total $\mathrm{N}$ on Trinervitermes soil than on Odontotermes soil, 4.5 times as much as Macrotermes soil and 8 times more than the plants on the control soil. The absolute $\mathrm{N}$ in the leaves $(\mathrm{N} / \mathrm{l} 00 \mathrm{~g})$ varied between soil treatments $\left(F_{3,72}=23.34, P<0.001\right)$ and species $\left(F_{1,72}=15.03, P<0.001\right)$ with the

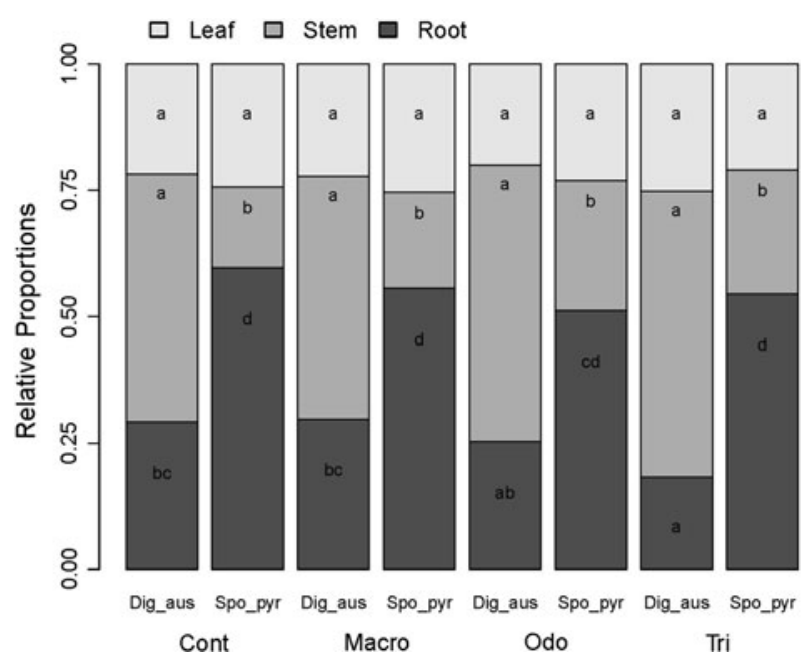

Figure 3. Greenhouse bioassay results; bar plot showing the differences in plant part allocation (roots, stems, and leaves) of the two grass species used, Dig_aus, Digitaria australe; Spo_pyr, Sporobolus pyramidalis in each soil treatment; Cont, Control soil; Macro, Macrotermes soil; Odo, Odontotermes soil; Tri, Trinervitermes soil. The data were log transformed for analysis; different letters denote significant differences $(P<0.05)$ in post-hoc Tukey's test. 
least $N$ in the leaves of the bunch grass on Trinervitermes soil.

\section{Field Experiment Results}

Pre-treatment measurements showed that there were no significant differences in the percent ground cover of any of the variables measured (Lawn $F_{4,45}=0.70, P=0.601$, Bunch $F_{4,45}=0.60$, $P=0.67$, Forbs $F_{4,45}=0.51, P=0.73$, Bare $F_{4,45}=$ $1.02 P=0.43$, Biomass $F_{4,25}=1.04 P=0.42$ ). In all plots, regardless of treatment and including the control plots, there was an increase in percentage ground cover of lawn grass $\left(F_{4,276}=\right.$ 9.5992, $P=<0.0001)$, bare ground $\left(F_{4}, 276=\right.$ 7.05343, $P=<0.0001)$ and greenness of the vegetation $\left(F_{4,276}=2.93048, P=<0.05\right)$, and a decrease in bunch grass $\left(F_{4,276}=8.9969, P=<0.0001\right)$ and forbs $\left(F_{4,276}=7.05343, P=<0.0001\right)$ after the start of the experiment (Figure 4). Addition of Macrotermes soil resulted in the most increase in cover of lawn grass and corresponding decrease in cover of bunch grass and forbs. Plots where Odontotermes soil was applied showed the least change in lawn and bunch grass cover but the largest increase in bare ground. Trinervitermes plots showed the least overall change. Vegetation on the Macrotermes and Odontotermes soil plots was greener than on the control plots with a trend toward more greenness on the Trinervitermes plots (Figure 4). The biomass of vegetation measured $\left(\mathrm{g} / \mathrm{m}^{2}\right) \quad\left(F_{4,276}=1.38, P=0.24\right)$, the sampled grass leaf:stem ratio $\left(F_{4,4}=0.72, P=0.62\right)$, live:dead ratio $\left(F_{4,4}=0.55, P=0.71\right)$ or total biomass $\left(F_{4,4}=0.68\right.$, $P=0.65)$ did not vary significantly among treatments.

\section{Soil Analysis}

All termite soils used in the field experiment had elevated levels of total $\mathrm{N}, \mathrm{C}, \mathrm{NO}_{3}{ }^{-}, \mathrm{NH}_{4}{ }^{+}$, extractable $\mathrm{P}, \mathrm{K}^{+}$, and $\mathrm{Ca}_{2}{ }^{+}$when compared to the non-termite soil (Table 2). The non-termite soil had the highest levels of extractable $\mathrm{Na}$ (see Table 2 for $P$ and $F$ values of results). The biggest differences were seen in extractable $\mathrm{NO}_{3}{ }^{-}$and $\mathrm{Mg}_{2}{ }^{+}$; all four soils differed significantly with Trinervitermes soil having more than 100 times more extractable nitrate than the non-termite soil. Generally, Trinervitermes soil had the highest inorganic nutrient and organic matter levels and was most significantly different from the other three soils. Macrotermes had higher levels of cations, specifically $\mathrm{Ca}$ and $\mathrm{Na}$, then the other two mound soils. There was more variance in the textural properties than the chemical properties of the soil. Macrotermes had more clay and silt and less medium and coarse sand particles than the nontermite soil. Odontotermes also had elevated amounts of clay particles and more medium sand particles. Trinervitermes soils most resembled the structure of the background soil although it also differed in silt and medium sized sand particles.

\section{Discussion}

Our results show that termite mound soils strongly influence the vegetation growing in them. The greenhouse bioassay shows that with the addition of termite mound soils, specifically Trinervitermes soil, both grasses responded with a large increase in total biomass and relative growth rate (Figure 2). This is probably an effect of the high levels of

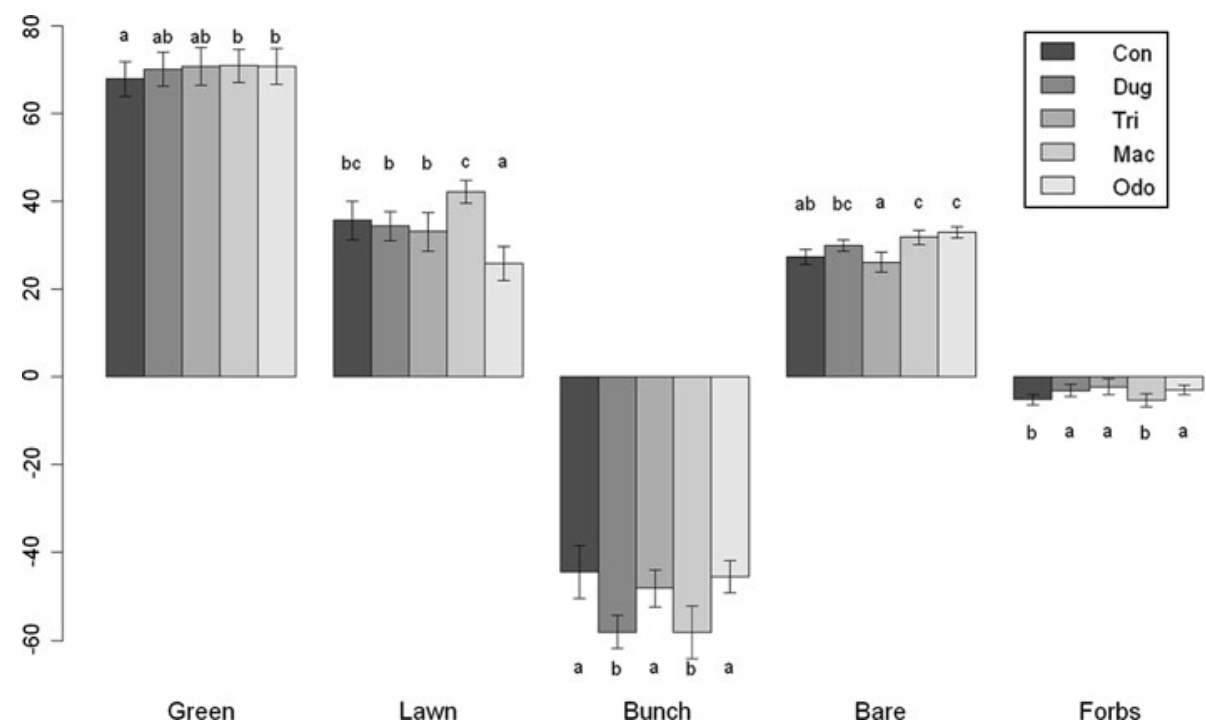

Figure 4. Field experiment results; bar plot showing the change in percentage ground cover to the end of the experiment relative to the start conditions for all soil treatments. Legend shows the different treatment types; Con, control plots; Dug, non-termite soil, Tri, Trinervitermes mound soil; Mac, Macrotermes mound soil; Odo, Odontotermes mound soil. Error bars indicate standard errors; different letters denote significant differences $(P<0.05)$ in post-hoc Tukey's test. 
Table 2. Soil Characteristics of Samples From Several Termite Mounds of Three Different Termite Genera and Control Soil (Dug) From $20 \mathrm{~cm}$ Below the Surface Away From Any Termite Mounds

\begin{tabular}{lccccc}
\hline & Dug & Trinervitermes & Macrotermes & Odontotermes & $F_{(3,8)}$ \\
\hline Chemical properties & & & & & \\
\% Nitrogen & $0.11^{\mathrm{a}}$ & $0.31^{\mathrm{d}}$ & $0.16^{\mathrm{b}}$ & $0.19^{\mathrm{c}}$ & $1167.25^{* * *}$ \\
\% Carbon & $1.44^{\mathrm{a}}$ & $4.29^{\mathrm{c}}$ & $1.46^{\mathrm{a}}$ & $2.12^{\mathrm{b}}$ & $1174.42^{* * *}$ \\
Extractable nitrate & $0.003^{\mathrm{a}}$ & $10.29^{\mathrm{d}}$ & $7.5^{\mathrm{c}}$ & $6.58^{\mathrm{b}}$ & $3129.41^{* * *}$ \\
Extractable ammonia & $0.17^{\mathrm{a}}$ & $0.86^{\mathrm{c}}$ & $0.34^{\mathrm{b}}$ & $0.34^{\mathrm{b}}$ & $138.84^{* * *}$ \\
Extractable P & $46.44^{\mathrm{a}}$ & $67.49^{\mathrm{c}}$ & $47.03^{\mathrm{a}}$ & $59.64^{\mathrm{b}}$ & $297.31^{* * *}$ \\
Water extractable P & $5.79^{\mathrm{b}}$ & $10.40^{\mathrm{c}}$ & $3.45^{\mathrm{a}}$ & $4.36^{\mathrm{ab}}$ & $71.17^{* * *}$ \\
Extractable K & $21.15^{\mathrm{a}}$ & $57.98^{\mathrm{c}}$ & $25.79^{\mathrm{b}}$ & $19.70^{\mathrm{a}}$ & $806.50^{* * *}$ \\
Extractable Ca & $63.09^{\mathrm{a}}$ & $193.97^{\mathrm{b}}$ & $259.02^{\mathrm{c}}$ & $191.28^{\mathrm{b}}$ & $886.12^{* * *}$ \\
Extractable Mg & $52.00^{\mathrm{b}}$ & $59.69^{\mathrm{d}}$ & $58.26^{\mathrm{c}}$ & $40.47^{\mathrm{a}}$ & $2068.38^{* * *}$ \\
Extractable Na & $20.71^{\mathrm{d}}$ & $10.53^{\mathrm{b}}$ & $15.31^{\mathrm{c}}$ & $6.86^{\mathrm{a}}$ & $1372.51^{* * *}$ \\
pH H2O & $5.83^{\mathrm{a}}$ & $6.02^{\mathrm{b}}$ & $6.95^{\mathrm{b}}$ & $6.51^{\mathrm{c}}$ & $1898.00^{* * *}$ \\
pH KCl & $4.89^{\mathrm{d}}$ & $5.58^{\mathrm{c}}$ & $6.45^{\mathrm{a}}$ & $6.03^{\mathrm{b}}$ & $1726.15^{* * *}$ \\
Organic mater & $4.15^{\mathrm{a}}$ & $9.26^{\mathrm{d}}$ & $4.80^{\mathrm{b}}$ & $5.72^{\mathrm{c}}$ & $350.59^{* * *}$ \\
Loss on ignition & $5.40^{\mathrm{a}}$ & $10.55^{\mathrm{d}}$ & $6.52^{\mathrm{b}}$ & $7.06^{\mathrm{c}}$ & $388.86^{* * *}$ \\
Texture & & & & \\
$<2 \mu \mathrm{m}$ vol.\% (clay) & $16.10^{\mathrm{a}}$ & $15.27^{\mathrm{a}}$ & $20.23^{\mathrm{c}}$ & $17.93^{\mathrm{b}}$ & $48.11^{* * *}$ \\
$<16 \mu \mathrm{m}$ vol.\% (silt) & $14.07^{\mathrm{a}}$ & $15.97^{\mathrm{b}}$ & $22.80^{\mathrm{c}}$ & $15.63^{\mathrm{a}}$ & $114.24^{* * *}$ \\
$<100 \mu \mathrm{m}$ vol.\% (fine sand) & $23.13^{\mathrm{b}}$ & $22.60^{\mathrm{ab}}$ & $23.13^{\mathrm{b}}$ & $20.97^{\mathrm{a}}$ & $7.65^{* *}$ \\
$<250 \mu \mathrm{m}$ vol.\% (medium sand) & $22.43^{\mathrm{b}}$ & $24.50^{\mathrm{c}}$ & $16.73^{\mathrm{a}}$ & $28.90^{\mathrm{d}}$ & $153.40^{* * *}$ \\
$<2000 \mu \mathrm{m}$ vol.\% (coarse sand) & $24.27^{\mathrm{b}}$ & $21.67^{\mathrm{b}}$ & $17.10^{\mathrm{a}}$ & $16.57^{\mathrm{a}}$ & $14.88^{* *}$ \\
\end{tabular}

Different letters denote significant differences in post-hoc Tukey's test after a one-way ANOVA. F values are shown $(* * * P<0.001, * * P<0.01)$. All units are mg per $100 \mathrm{~g}$ of dry soil unless otherwise stated.

inorganic nutrients, especially available $\mathrm{P}$ and $\mathrm{N}$, found in Trinervitermes soil in this study (Table 2) and for mounds of similar genera elsewhere (Smith and Yeaton 1998; López-Hernández 2001; Ackerman and others 2007). In addition to the increase in total biomass, there was also a change in allocation patterns for both grasses in Trinervitermes soil (Figure 3). The bunch grasses invested most in roots whereas the lawn grasses invested more in stems. The lawn grass investment in stems stimulates its stoloniferous growth, which allows it to colonize a disturbed patch faster than the bunch grasses which are obligate seed producers and so cannot spread as quickly locally (Coughenour 1985). As we used only one species of bunch and one of lawn grass and the starting conditions in the greenhouse differed slightly, generalizations should be made with caution. However, the findings fit well with current hypotheses that lawn grasses spread after disturbance, especially in the presence of nutrient rich soil (Blackmore and others 1990; Scholes and Walker 1993; Young and others 1995; Cromsigt and Olff 2008). Other studies on the influence of termite mounds on vegetation patterns have referred to the higher levels of available nutrients to explain the presence of palatable or lawn grass species around them (Arshad 1982; Spain and McIvor 1988; Smith and Yeaton 1998).

In the field experiment, all plots showed large changes in their vegetation composition. The ground cover of lawn grasses and bare ground increased in all the plots, as did the greenness of the plants, while cover of bunch grasses and forbs declined. This overall effect was most likely due to our mowing treatment. By cutting the vegetation, we probably favored lawn grasses as they are able to respond most quickly to loss of biomass, especially with increased availability of light resulting from the removal of tall grass stands (Coughenour 1985; Cromsigt and Olff 2008). Although all the plots changed, responses differed between soil treatments. The addition of Macrotermes soil induced the greatest community shift to a lawn grass state in combination with the cutting treatment. There are several important differences between the conditions in the field experiment and the greenhouse, including interspecific competition and the response of mature plants versus seedlings and small clones. It is possible that the mature plants with resource reserves may have reacted differently to the young plants in the greenhouse. However, we propose that the disparity of results 
between the field experiment and the greenhouse occurs due to changes in interspecific competition caused by interactions with large herbivores. The soil analysis (Table 2) shows Macrotermes soil has a combination of high levels of $\mathrm{Na}$ and $\mathrm{Ca}$. Both are important limiting minerals for mammalian herbivores in most terrestrial systems (Tracy and McNaughton 1995 and references therein). In savannahs, a variety of mammals are known to seek out areas of salt enrichment (McNaughton 1988; Ruggiero and Fay 1994; Holdo and others 2002). Therefore, addition of mineral rich Macrotermes soil may have made these plots more attractive to herbivores than surrounding plots. Continued intense grazing in the Macrotermes plots might have facilitated the colonization of these plots by the grazing tolerant lawn species making them competitively superior over the otherwise dominant bunch grasses. Because we do not have data on herbivore visitation per plot this suggestion remains speculative. However, we believe it is a probable explanation because other experimental studies have shown that lawn grass species can only colonize grassland plots under continuous intense grazing (O'Connor 1994; McNaughton and others 1997; Cromsigt and Olff 2008).

An alternative explanation is that the addition of Macrotermes soil, with the highest clay and silt content (Table 2), changed the texture of the background soil resulting in the largest increase in lawn grass cover. However, we feel that this is unlikely as there was no disturbance to the soil surface or to the grass roots. This explanation is also challenged by further comparison of the other soils; the next highest levels of clay were found in the Odontotermes soil, and silt in the Trinervitermes soils, but these soils did not show a similar increase in lawn grass. In fact, the most similar changes in lawn/bunch cover were seen in the plots where the sub surface (dug) soil was applied, which although texturally different, had Na levels most similar to the Macrotermes soil. The fact that the non-termite soil contained high levels of $\mathrm{Na}$, but did not show as strong an increase in lawn cover as Macrotermes soil, suggests that $\mathrm{Ca}$ might have been more important in attracting herbivores (Maduakor and others 1995).

The differences in nutrient concentrations between the mound soils can be linked to the mound structure and function. The concentrations of available $\mathrm{N}$ and $\mathrm{P}$ in the Trinervitermes mounds (Smith and Yeaton 1998; López-Hernández 2001; Ackerman and others 2007) are related to the high organic matter content of these mound soils, constructed from top soil, mucus and fecal material (Uys 2002) and used to store plant matter throughout (C. Gosling, personal observation). Macrotermitinae mounds (including Macrotermes and Odontotermes) function primarily as climate control chambers for the symbiotic fungi grown on fungal combs deep within the mounds (Noirot and Darlington 2000). The large structures required to create a homeostatic environment for the fungi, results in the need for robust and stable building materials. Macrotermitinae have been shown to preferentially choose and relocate fine soil particles, especially clay, for this purpose (Lobry de Bruyn and Conacher 1990; Holt and Lepage 2000; Jouquet and others 2004b). These soils are often brought from deep soil layers and have been reported as having higher levels of exchangeable cations than the surrounding soils (Holt and Lepage 2000; Sileshi and others 2010). Although our texture analysis showed the Macrotermes and Odontotermes mound material is largely fine particles with significantly more clay than the surrounding soil this did not result in a higher cation exchange capacity. There were significant differences among all soils for all cation exchange minerals measured ( $\mathrm{K}, \mathrm{Ca}, \mathrm{Mg}$, and $\mathrm{Na}$ ). As reported in other studies (Jouquet and others 2005a), there were also significant differences in the properties and effects of the two Macrotermitinae mounds. Although Odontotermes, like Macrotermes, have large, complex nest structures for optimal fungal growth, these tend to be largely subterranean. The absence of a big epigeal structure reduces the need for clays as a stable building material and therefore, reduces the mineral content of these soils. This offers an explanation for the intermediate results obtained from the Odontotermes soil used here. Therefore, we confirm that the variation in mounds size, structure, and function strongly influences the nutrient concentrations in the mound soils. The influence that mound soils have on the surrounding area depends on the density and distribution of the mounds. In our study area, the density of mounds, 3.07/ha (Table 1), was three times higher than that found in Kruger National Park (Meyer and others 1999; Levick and others 2010). In Kruger National Park, despite the much lower densities than in our site, Levick and others (2010) showed that mounds affected $20 \%$ of the landscape. In that study, and most others, it is also important to consider that only a small proportion of termite activity is detected. Levick and others (2010) used a remote sensing tool to estimate termite mound density and hence, only considered fairly large, aboveground, mounds. In our study we used mound soils of only three of 54 genera recorded in southern Africa (54 genera recorded in southern Africa, Uys 2002). A 
large proportion of termite activity, including subterranean, is hard to detect even with intensive field surveys. In addition, nutrient-rich soil is not only distributed over the surrounding area by mound erosion but also from other foraging structures (Jouquet and others 2007). Estimates of this soil addition in African savannas range from 300$900 \mathrm{~kg} / \mathrm{ha} /$ year for a single species (Bagine 1984 and references therein), to a total from all termites of 10,000 kg/ha/year (Wood 1988). This then must have large and varied effects on the surrounding vegetation.

Our work has shown that termite mound soils have the potential to shape the dynamics between co-occurring grass species. The nutrients in the soil of mounds used for storage, such as Trinervitermes mounds, have a fertilization effect on both bunch and lawn grass plants. If the aboveground portion of the grasses is frequently removed by grazing (or in our case, mowing), the increased nutrient availability could allow lawn grasses to spread as they are able to utilize these nutrients more quickly than the bunch grasses. Our field results showed that this effect was much stronger with Macrotermes soil, rather than Trinervitermes soil. We speculate that clayey, mineral-rich, Macrotermes soil attracts herbivores (Maduakor and others 1995) that create the necessary disturbance which in turn affects the lawn-bunch balance by favoring the grazing tolerant lawn grass species. Hence, our work shows that different termite genera can have strongly differing effects on soil nutrient availability and the vegetation growing on these soils caused by differences in mound structure and functioning. As a result, generalizations about the effects of termite mounds on nutrient availability and vegetation should be made with care. Although it is difficult to generalize effects of termites across genera, we confirm that the termite mounds examined here can play an important role in creating and maintaining heterogeneity in savannahs.

\section{ACKNOWLEDGMENTS}

We would like to thank Abednigo Mkwanazi, Alejandro Ordonez, Ciska Veen, Dave Robertson, Jacob Hogendorf, Jan Graf, Johan Ngobese, Matt Waldram, Nikki Stevens, Nellie Eck, Sue van Rensburg, the ZLTP team and Ezemvelo KZN Wildlife for helping with the completion of this work and the Agricultural Research Council of South Africa for kind permission to use their material in Figure 1. We also thank two anonymous reviewers and Dr. De Deyn whose helpful comments improved a previous version of this manuscript. Finally, JPGMC was supported by a Marie Curie European Integration Grant under the 7th framework program with grant agreement number PIEF-GA-2008-220947.

\section{OPEN ACCESS}

This article is distributed under the terms of the Creative Commons Attribution Noncommercial License which permits any noncommercial use, distribution, and reproduction in any medium, provided the original author(s) and source are credited.

\section{REFERENCES}

Ackerman IL, Teixeira WG, Riha SJ, Lehmann J, Fernandes ECM. 2007. The impact of mound-building termites on surface soil properties in a secondary forest of Central Amazonia. Appl Soil Ecol 37:267-76.

Archibald S. 2008. African grazing lawns-how fire, rainfall, and grazer numbers interact to affect grass community states. J Wildl Manage 72:492-501.

Archibald S, Bond WJ, Stock WD, Fairbanks DHK. 2005. Shaping the landscape: fire-grazer interactions in an African savanna. Ecological Applications 15:96-109.

Arshad MA. 1982. Influence of the termite Macrotermes michaelseni (Sjost) on soil fertility and vegetation in a semi-arid savannah ecosystem. Agro-Ecosystems 8:47-58.

Bagine RKN. 1984. Soil translocation by termites of the genus Odontotermes (Holmgren) (Isoptera: Macrotermitinae) in an arid area of Northern Kenya. Oecologia 64:263-6.

Balfour DA, Howison OE. 2001. Spatial and temporal variation in a mesic savanna fire regime: responses to variation in annual rainfall. African Journal of Range and Forage Science $19: 43-51$

Bignell DE. 2000. Introduction to symbiosis. In: Abe T, Bignel DE, Higashi M, Eds. Termites: evolution, sociality, symbiosis, ecology. Dordrecht: Kluwer Academic Publishers. p 189-208.

Bignell DE, Eggleton P. 2000. Termites in Ecosystems. In: Abe T, Bignell DE, Higashi M, Eds. Termites: evolution, sociality, ecology. Dordrecht: Kluwer Academic Publishers. p 363-87.

Blackmore AC, Mentis MT, Scholes RJ. 1990. The origin and extent of nutrient-enriched patches within a nutrient-poor Savanna in South-Africa. J Biogeogr 17:463-70.

Bonnet O, Fritz H, Gignoux J, Meuret M. 2010. Challenges of foraging on a high-quality but unpredictable food source: the dynamics of grass production and consumption in savanna grazing lawns. J Ecol 98:908-16.

Brooks PM, Macdonald IAW, Owen-Smith RN. 1983. The Hluhluwe-Umfolozi Reserve: an ecological case history. Management of large mammals in African conservation areas. Pretoria: Haum Educational Publishers. pp 51-7.

Coughenour MB. 1985. Graminoid responses to grazing by large herbivores-adaptations, exaptations, and interacting processes. Ann Mo Bot Garden 72:852-63.

Coventry RJ, Holt JA, Sinclair DF. 1988. Nutrient cycling by mound building termites in low fertility soils of semi-arid tropical Australia. Aust J Soil Res 26:375-90. 
Cromsigt JPGM, Olff H. 2006. Resource partitioning among savanna grazers mediated by local heterogeneity: an experimental approach. Ecology 87:1532-41.

Cromsigt JPGM, Olff H. 2008. Dynamics of grazing lawn formation: an experimental test of the role of scale-dependent processes. Oikos 117:1444-52.

Dangerfield JM, McCarthy TS, Ellery WN. 1998. The moundbuilding termite Macrotermes michaelseni as an ecosystem engineer. J Trop Ecol 14:507-20.

Darlington J, Dransfield R. 1987. Size relationships in nest populations and mound parameters in the termite Macrotermes michaelseni in Kenya. Insectes Sociaux (Historical Archive) 34:165-80.

Davies AB, Parr CL, van Rensburg BJ. 2010. Termites and fire: current understanding and future research directions for improved savanna conservation. Aust Ecol 35:482-6.

Deshmukh I. 1989. How important are termites in the production ecology of African Savannas. Sociobiology 15:155-68.

Du Toit JT, Rogers KH, Biggs HC. 2003. The Kruger experience: ecology and management of savanna heterogeneity. Washington: Island Press.

Eggleton P, Bignell DE, Sands WA, Mawdsley NA, Lawton JH, Wood TG, Bignell NC. 1996. The diversity, abundance and biomass of termites under differing levels of disturbance in the Mbalmayo Forest Reserve, Southern Cameroon. Philos Trans 351:51-68.

Ferrar P. 1982a. Termites of a South African Savanna. Oecologia 52:133-8.

Ferrar P. 1982b. Termites of a South African Savanna IV. Subterranean populations, mass determinations and biomass estimations. Oecologia 52:147-51.

Fox-Dobbs K, Doak DF, Brody AK, Palmer TM. 2010. Termites create spatial structure and govern ecosystem function by affecting $\mathrm{N}^{2}$ fixation in an East African savanna. Ecology 91:1296-307.

Grant CC, Scholes MC. 2006. The importance of nutrient hotspots in the conservation and management of large wild mammalian herbivores in semi-arid savannas. Biological Conservation 130:426-37.

Holdo RM, Dudley JP, McDonald LR. 2002. Geophagy in the African elephant in relation to the availability of dietary sodium. J Mammal 83:652-64.

Holt JA, Coventry RJ. 1990. Nutrient cycling in Australian savannas. J Biogeogr 17:427-32.

Holt JA, Lepage M. 2000. Termites and soil properties. In: Abe T, Bignell DE, Higashi M, Eds. Termites: evolution, sociality, symbioses, ecology. Dordrecht: Kluwer Academic Publishers. p 389-407.

Hopkins B. 1966. Vegetation of the Olokemeji forest reserve Nigeria. 4. Litter and soil with special reference to their seasonal changes. J Ecol 54:687.

Huisman J, Olff H. 1998. Competition and facilitation in multispecies plant-herbivore systems of productive environments. Ecol Lett 1:25-9.

Jones CG, Lawton JH, Shachak M. 1997. Positive and negative effects of organisms as physical ecosystem engineers. Ecology 78:1946-57.

Jouquet P, Barre P, Lepage M, Velde B. 2005a. Impact of subterranean fungus-growing termites (Isoptera, Macrotermitiane) on chosen soil properties in a West African savanna. Biol Fertil Soils 41:365-70.
Jouquet P, Bottinelli N, Lata JC, Mora P, Caquineau S. 2007. Role of the fungus-growing termite Pseudacanthotermes spiniger (Isoptera, Macrotermitinae) in the dynamic of clay and soil organic matter content. An experimental analysis. Geoderma 139:127-33.

Jouquet P, Boulain N, Gignoux J, Lepage M. 2004a. Association between subterranean termites and grasses in a West African savanna: spatial pattern analysis shows a significant role for Odontotermes n. pauperans. Appl Soil Ecol 27:99-107.

Jouquet P, Tavernier V, Abbadie L, Lepage M. 2005b. Nests of subterranean fungus-growing termites (Isoptera, Macrotermitinae) as nutrient patches for grasses in savannah ecosystems. Afr J Ecol 43:191-6.

Jouquet P, Tessier D, Lepage M. 2004b. The soil structural stability of termite nests: role of clays in Macrotermes bellicosus (Isoptera, Macrotermitinae) mound soils. Eur J Soil Biol 40:23-9.

Konate S, Le Roux X, Tessier D, Lepage M. 1998. Influence of large termitaria on soil characteristics, soil water regime, and tree leaf shedding pattern in a West African Savanna. Plant Soil 206:47-60.

Lavelle P. 2002. Functional domains in soils. Ecol Res 17:441-50.

Lavelle P, Decaëns T, Aubert M, Barot S, Blouin M, Bureau F, Margerie P, Mora P, Rossi JP. 2006. Soil invertebrates and ecosystem services. Eur J Soil Biol 42:S3-15.

Lee KE, Wood TG. 1971. Termites and soil. London: Academic Press.

Levick SR, Asner GP, Kennedy-Bowdoin T, Knapp DE. 2010. The spatial extent of termite influences on herbivore browsing in an African savanna. Biological Conservation 143:2462-7.

Lobry de Bruyn LA, Conacher AJ. 1990. The role of termites and ants in soil modification: a review. Aust J Soil Res 28:55-93.

López-Hernández D. 2001. Nutrient dynamics (C, N and P) in termite mounds of Nasutitermes ephratae from savannas of the Orinoco Llanos (Venezuela). Soil Biol Biochem 33:747-53.

Maduakor HO, Okere AN, Onyeanuforo CC. 1995. Termite mounds in relation to the surrounding soils in the forest and derived savanna zones of southeastern Nigeria. Biol Fertil Soils 20:157-62.

McNaughton SJ. 1988. Mineral nutrition and spatial concentrations of African ungulates. Nature 334:343-5.

McNaughton SJ, Banyikwa FF, McNaughton MM. 1997. Promotion of the cycling of diet-enhancing nutrients by African grazers. Science 278:1798-900.

Meyer VW, Braack LEO, Biggs HC, Ebersohn C. 1999. Distribution and density of termite mounds in the northern Kruger National Park, with specific reference to those constructed by Macrotermes Holmgren (Isoptera: Termitidae). Afr Entomol 7:123-30.

Moe S, Mobæk R, Narmo A. 2009. Mound building termites contribute to savanna vegetation heterogeneity. Plant Ecol 202:31-40.

Noirot C, Darlington J. 2000. Termite nests: architecture, regulation and defense. In: Abe T, Bignel DE, Higashi M, Eds. Termites: evolution, sociality, symbiosis, ecology. Dordrecht: Kluwer Academic Publishers. p 121-39.

O'Connor TG. 1994. Composition and population responses of an African Savanna grassland to rainfall and grazing. J Appl Ecol 31:155-71.

Owen-Smith N. 2004. Functional heterogeneity in resources within landscapes and herbivore population dynamics. Landsc Ecol 20:317. 
Pomeroy DE. 1983. Some effects of mound-building termites on the soils of a semi-arid area of Kenya. Journal of Soil Science 34:555-70.

Ruggiero RG, Fay JM. 1994. Utilization of termitarium soils by elephants and its ecological implications. Afr J Ecol 32:22232.

Scholes RJ, Walker BH. 1993. An African Savanna; synthesis of the Nylsvley study. Cambridge: Cambridge University Press.

Sileshi GW, Arshad MA, Konate S, Nkunika POY. 2010. Termiteinduced heterogenity in African savanna vegetation: mechanisms and patterns. J Veg Sci 21(5):923-937.

Sinclair ARE, Packer C, Mduma SAR, Fryxell JM. 2008. Serengeti III human impacts on ecosystem dynamics. Chicago: University of Chicago Press.

Smith FR, Yeaton RI. 1998. Disturbance by the mound-building termite, Trinervitermes trinervoides, and vegetation patch dynamics in a semi-arid, southern African grassland. Plant Ecology 137:41-53.

Spain AV, McIvor JG. 1988. The nature of herbaceous vegetation associated with termitaria in North-Eastern Australia. J Ecol 76:181-91.

Stock WD, Bond WJ, van de Vijver CADM. 2009. Herbivore and nutrient control of lawn and bunch grass distributions in a southern African savanna. Plant Ecology 206:15-27.

Tracy BF, McNaughton SJ. 1995. Elemental analysis of mineral lick soils from the Serengeti National Park, the Konza Prairie and Yellowstone National Park. Ecography 18:91-4.
Uys V. 2002. A guide to the termite genera of southern Africa. Plant Protection Research Institute Handbook No. 15. Pretoria: Agricultural Research Council.

Van Oudtshoorn F. 1992. Guide to grasses of Southern Africa. Pretoria: Briza Publicatios.

Verweij RJT, Verrelst J, Loth P, Heitkonig IMA, Brunsting AMH. 2006. Grazing lawns contribute to the subsistence of mesoherbivores on dystrophic savannas. Oikos 114:108-16.

Waldram M, Bond W, Stock W. 2008. Ecological engineering by a mega-grazer: White Rhino impacts on a South African Savanna. Ecosystems 11:101-12.

Whateley A, Porter RN. 1983. The woody vegetation communities of the Hluhluwe-Corridor-Umfolozi Game Reserve Complex. Bothalia 14:745-58.

Wood TG. 1988. Termites and the Soil Environment. Biology and Fertility of Soils 6:228-36.

Wood TG, Sands W, Brian MV. 1978. The role of termites in ecosystems. Production ecology of ants and termites. Cambridge: Cambridge University Press. pp 245-92.

Young TP, Patridge N, Macrae A. 1995. Long-term glades in Acacia Bushland and their edge effects in Laikipia, Kenya. Ecol Appl 5:97-108. 